\title{
Prospective Randomized Control Trial Comparing Effect of Dexamethasone Versus Fentanyl as Adjuvants to Intrathecal Bupivacaine for Orthopedic Surgery
}

\author{
Harjot Kaur ${ }^{1}$, Rajesh Misra ${ }^{1}$, Shelly Mittal ${ }^{1}$, Gur Aziz Singh Sidhu ${ }^{2}$ \\ 1. Anesthesia, Artemis Hospitals, Gurgaon, IND 2. Orthopedics, Medanta Hospital, Gurgaon, IND
}

Corresponding author: Harjot Kaur, drharjotgill@gmail.com

\begin{abstract}
Introduction

Spinal anesthesia is the most consistent block for lower limb orthopedic surgeries. We conducted this randomized prospective study to evaluate comparative efficacy of intrathecal dexamethasone with fentanyl and normal saline as adjuvants to hyperbaric bupivacaine in spinal anesthesia administered to patients scheduled for lower limb orthopedic surgery.
\end{abstract}

\section{Materials and methods}

105 patients scheduled for lower limb orthopedic surgeries under spinal anesthesia were included in this clinical trial. After randomization, patients received an intrathecal injection of hyperbaric bupivacaine (12.5 $\mathrm{mg}$ ) with $4 \mathrm{mg}$ of dexamethasone in group I, hyperbaric bupivacaine $(12.5 \mathrm{mg})$ with $25 \mathrm{ug}$ fentanyl with 0.5 $\mathrm{ml}$ of normal saline in group II and hyperbaric bupivacaine $(12.5 \mathrm{mg})$ with normal saline $(1 \mathrm{ml})$ in group III, so as to make volume of drug equal in all three groups. The observer evaluated the sensory and motor blocks and other parameters like time to self-void, stay in post-anesthesia care unit (PACU) and complications.

\section{Results}

The total duration of sensory blockade was found to be 311.43, 197.86 and 115.29 minutes and motor blockade of 223.43, 163.86 and 83.0 minutes in groups I, II and III respectively. The PACU stay was 233.14, 173.86 and 93.00 minutes in groups I, II and III, respectively. The average time to self-void was 400.00 , 315.29 and 203.00 in three groups, respectively.

\section{Conclusion}

Intrathecal dexamethasone seemed to be an effective adjuvant to spinal bupivacaine as it prolongs the duration of analgesia, stable hemodynamic profile with minimal side effects. Further studies are required to evaluate the optimum dose and long-term safety of intrathecal dexamethasone.

Review began 03/10/2021 Review ended 03/15/2021 Published 03/17/2021

\section{() Copyright 2021}

Kaur et al. This is an open access article distributed under the terms of the Creative Commons Attribution License CC-BY 4.0., which permits unrestricted use, distribution, and reproduction in any medium, provided the original author and source are credited.
Categories: Anesthesiology, Pain Management, Orthopedics

Keywords: spinal anesthesia, adjuvants, dexamethasone, fentanyl, motor blockade, sensory blockade

\section{Introduction}

Spinal anesthesia is the most consistent block for lower limb orthopedic surgeries as it provides excellent anesthesia, minimal cognitive dysfunction, and post-operative analgesia. Moreover, less incidence of postoperative nausea and vomiting, cardiovascular or respiratory complications and better post-operative pain relief and the patient's ability to communicate are added advantages [1]. Various agents have been used in subarachnoid block as adjuvants such as epinephrine, phenylephrine, clonidine, opioids, etc. to prolong the effect of spinal anesthesia [1,2]. However, every adjuvant has its own advantages and disadvantages. The use of epinephrine (> $10 \mathrm{microg} / \mathrm{mL}$ ) as adjuvant causes tachycardia, pallor, and hypertension; which can be detrimental in patients with cardiovascular disease [3]. Intrathecal opioids cause pruritus, urinary retention, respiratory depression and occasionally severe nausea and vomiting that may limit their use [4].

Recently, literature reports few studies on prolongation of sensory blockade in peripheral nerves both in quantitative as well as qualitative way after addition of corticosteroids [1,5]. Local anesthetics act by blocking the sodium channels, whereas dexamethasone relieves pain by reducing inflammation and blocking transmission of nociceptive C-fibers and by suppressing ectopic neural discharge in abnormal nerves [6]. It has been shown that the duration of post-operative analgesia was prolonged when dexamethasone was given as an adjunct for peripheral nerve blocks [7]. We found that a very few studies in the literature reported the intrathecal use of dexamethasone as an adjuvant $[8,9]$. Hence keeping this in view, we conducted this study to evaluate comparative efficacy of intrathecal dexamethasone, fentanyl and normal 
saline as adjuvants to hyperbaric bupivacaine in spinal anesthesia administered to patients scheduled for lower limb orthopedic surgery.

\section{Materials And Methods}

After the approval from the scientific and research ethics committee, written informed consent was obtained from each patient enrolled in the study. Patients with American Society of Anesthesiologist (ASA) class I-II, between 18 and 65 years old, scheduled for lower limb orthopedic surgeries under spinal anesthesia were included in this clinical trial. Patients with contraindications to spinal anesthesia, neurologic disease (multiple sclerosis, symptomatic lumbar herniated disc, spinal stenosis), fluid restriction (cardiac or renal insufficiency), allergy or intolerance to local anesthetics, history of long term steroid therapy, opium addiction or refusal to participate in the study were excluded from study.

Premedication with parenteral ranitidine $50 \mathrm{mg}$ and parenteral ondansetron $4 \mathrm{mg}$ was given in pre-operative room. Standard monitoring was used throughout the procedure, including non-invasive arterial blood pressure, electrocardiogram (five leads), and pulse oximetry. Sedation was provided at the discretion of the anesthesiologist (midazolam 0.025 to $0.05 \mathrm{mg} / \mathrm{kg}$ IV before or immediately after the spinal).

Spinal anesthesia was performed under sterile conditions after local infiltration of the skin with $2 \%$ lidocaine. With the patient in the sitting position, the subarachnoid space was entered at the L2-3, L3-4, or L4-5 interspace via the midline approach using a 27G Quincke spinal needle. We used computer randomization in which the patients and observer were blinded (double-blinded study). According to randomization, patients received an intrathecal injection of hyperbaric bupivacaine $(12.5 \mathrm{mg})$ with $4 \mathrm{mg}$ of dexamethasone in group I, hyperbaric bupivacaine $(12.5 \mathrm{mg}$ ) with $25 \mathrm{ug}$ fentanyl with $0.5 \mathrm{ml}$ of normal saline in group II and hyperbaric bupivacaine $(12.5 \mathrm{mg}$ ) with normal saline $(1 \mathrm{ml})$ in group III, so as to make volume of drug equal in all three groups. After the completion of the spinal injection, the patients were immediately placed supine. The observer (who was blinded and was not involved in the procedure) evaluated the sensory and motor blocks every one minute for 5 minutes or till the desired level of block was achieved, then every 15 minutes during the surgery and postoperatively until the sensory block had regressed to the L1 dermatome. The sensory level of the block was assessed in a caudal to cephalad direction using the loss of sensation to pinprick, and the forearm was used as the reference point. The motor block was assessed using the Modified Bromage scale. Readiness for surgery was defined as loss of sensation to pinprick at T10. During surgery, evaluation of the motor block was suspended until the end of the procedure.

If additional sedation was needed, midazolam 0.025 to $0.05 \mathrm{mg} / \mathrm{kg}$ IV or propofol 25 to $50 \mathrm{mcg} / \mathrm{kg} / \mathrm{min} \mathrm{IV}$ was administered. The total dose of any given medication was recorded. If the patient still felt pain, general anesthesia was provided and the patient was excluded from the study.

The occurrence of clinically relevant hypotension (defined as a decrease in systolic arterial blood pressure $20 \%$ from baseline values) was treated with IV injection mephentermine $6 \mathrm{mg}$. Clinically relevant bradycardia (defined as heart rate $<50$ beats/min) was treated with injection atropine $0.6 \mathrm{mg}$ IV. The cumulative dose of any of these medications or sedatives was recorded. The duration of sensory and motor block was recorded along with the side effects or complications (nausea, vomiting, hypotension, bradycardia, etc.) were recorded along with cumulative dose of additional agents used. The duration of sensory block was defined from peak of sensory block up to regression to L1 level or when the patient's felt pain in the field of surgery. Motor block duration was defined from peak of motor block (Modified Bromage score 3) to complete motor recovery (Modified Bromage score 0).

Patients were discharged from the post-anesthesia care unit (PACU) once they attained all of the following criteria: stable vital signs, signs of regression of the motor block (Bromage 0 to 2), no analgesia needed within the previous $20 \mathrm{~min}$ and normal consciousness. In the post-operative period, time to self-voiding of urine was noted. Incidence of post-operative shivering, nausea, vomiting, hypotension and bradycardia was recorded and compared. In post-operative period patients were assessed for pain by visual analogue scale (VAS), rescue analgesia and time to first post-operative analgesia were recorded. In post-operative period patients were assessed for pain by visual analogue scale (VAS) one hourly for the first four hours and then at four hourly intervals till 12 hours or till VAS more than 4 . Rescue analgesia was given in form of injection tramadol (100 mg in $100 \mathrm{ml}$ saline) intravenously if pain on VAS was more than 4.

The continuous data were shown as mean with standard deviation and categorical data was represented as absolute numbers and percentages. For continuous data, the Kolmogorov-Smirnov tests were performed to assess normality and where appropriate the data was analyzed with required statistical tests and descriptive statistics. Parametric data were analyzed with analysis of variance (ANOVA). Non-parametric data were analyzed Kruskal Wallis test. Nominal categorical data between the groups were compared using Chi-square test or Fisher's exact test as appropriate and use the correlation coefficient to observe the linear relationship.

\section{Results}

The patients in all the three groups were comparable with respect to age, sex, ASA class and the length of 


\section{Cureus}

surgical procedures. The onset of sensory and motor block was comparable among all the groups. The mean time of onset of sensory block (TOSB) in group I, group II and group III were $6.85( \pm 1.21), 7.65( \pm 1.25)$ and $7.20( \pm 1.47)$ minutes respectively. The mean time of onset of motor block (TOMB) in groups I, II and III was $9.22( \pm 1.47), 9.82( \pm 1.27)$ and $8.94( \pm 1.34)$ minutes, respectively. However, no statistically significant difference was found in three groups with relation to TOSB and TOMB. The duration of surgery in three the groups was found to be comparable with $86.14( \pm 15.02)$ minutes in group I, $88.29( \pm 13.39)$ minutes in group II and in group III the mean surgical duration was $86.20 \pm 13.45$ minutes which was statistically insignificant ( $p$ $=0.211$. .

The total duration of sensory blockade was found to be 311.43 (SD 13.59) minutes in group I, 197.86 (SD 12.14) minutes in group II and the group III reported 115.29 (SD 14.60) minutes of sensory blockade and was statistically significant $(\mathrm{p}<0.0001$ ) (Figure 1).The total duration of motor blockade was found to be $223.43 \pm 16.96$ minutes in group I, 163.86 \pm 12.49 minutes in group II and the group III reported 83.0 \pm 14.46 minutes of motor blockade and the difference was statistically significant $(\mathrm{p}<0.0001)$ (Figure 2$)$.

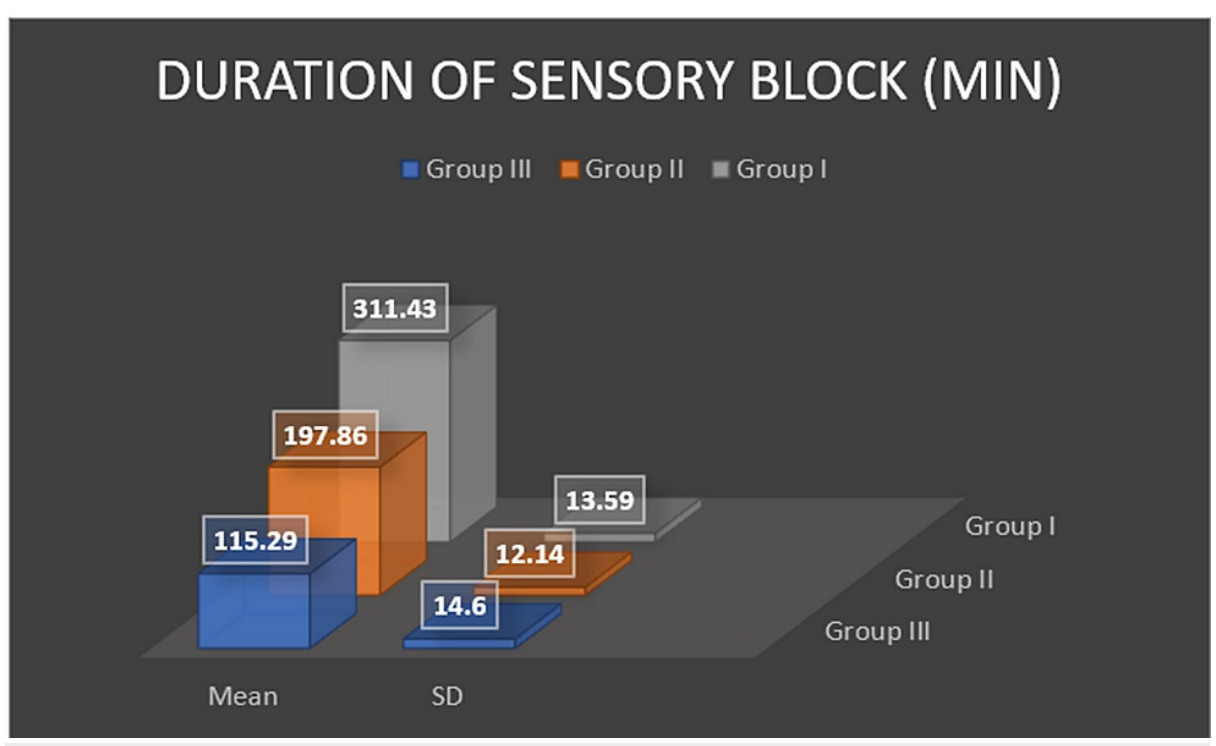

\section{FIGURE 1: Duration of sensory block.}

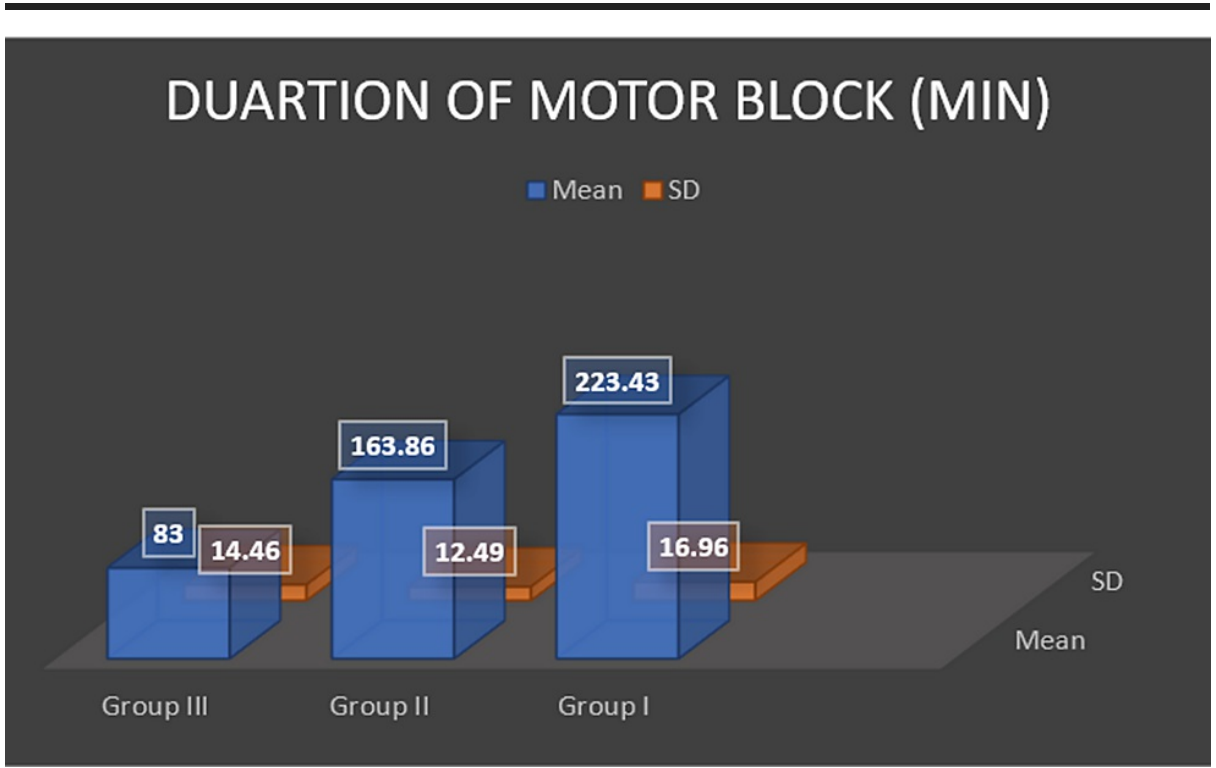

FIGURE 2: Duration of motor block.

The patients in group III stayed in the PACU for $93.00( \pm 14.46)$ minutes on the contrary the length of PACU stay was $173.86( \pm 12.49)$ minutes in the patients belonging to group II and $233.14( \pm 17.28)$ minutes in group I with $\mathrm{p}<0.0001$. The time taken to self-void was $400.00( \pm 29.13)$ minutes in group I, $315.29( \pm 21.18)$ minutes in group II and group III patients took $203.00( \pm 19.71)$ minutes to self-void. The difference amongst different 


\section{Cureus}

groups was statistically significant $(\mathrm{p}<0.0001)$.

Thirty (28.57\%) patients required rescue analgesia within four hours after the surgery. Rescue analgesia was given within two hours in 10 patients, eight patients had pain within three hours after surgery and only one patient did not have pain until four hours after surgery in group III. 11 patients in group II required rescue analgesia within four hours; however, in group I, none required rescue analgesia in first four hours (Figure 3). Prolonged duration of analgesia with significantly delayed time of administration of rescue analgesia was observed in group I compared to group II and III. The difference in time of first rescue analgesia in groups I, II and III was statistically significant $(\mathrm{p}<0.0001)$.



FIGURE 3: Rescue analgesia.

In group III, two patients had nausea/vomiting, one patient each had bradycardia, hypotension and shivering. In group II, seven patients had pruritus, four had nausea/vomiting, three patients had shivering and only one patient had hypotension. However, in group I only two patients had hypotension and no patients had complaints of nausea/vomiting, bradycardia, shivering or pruritus (Figure 4).



FIGURE 4: Post-operative complications.

\section{Discussion}

Early and effective management of postoperative pain allows early mobilization of patient after orthopedics surgery thus preventing the associated co-morbidities. Different combinations of drugs are used to target 
different phases of pain pathway from perception to central modulation. The addition of intrathecal adjuvants in spinal anesthesia offers hemodynamic stability along with prolongation of sensory block, longer postoperative analgesia and fewer undesirable effects [10].

Literature reported various studies showing the analgesic effects of steroids in neuraxial and peripheral blocks [11,12]. The results of our study demonstrated that supplementation of spinal bupivacaine with dexamethasone significantly prolonged sensory block, and postoperative analgesia compared with intrathecal bupivacaine alone or when fentanyl was used as an adjuvant with intrathecal bupivacaine, without any effect on the onset time of sensory or motor block in lower limb orthopedic surgeries.

A study by Fayyaz et al. compared the mean duration of analgesia with intrathecal bupivacaine alone versus intrathecal bupivacaine plus dexamethasone, for elective caesarean section [13]. They concluded that dexamethasone and hyperbaric bupivacaine provided $391 \pm 25.51$ minutes of analgesia as compared to hyperbaric bupivacaine alone $179.43 \pm 23.32$ minutes which was statistically significant. Our study reported similar results as total duration of sensory blockade was found to be $115.29 \pm 14.60$ minutes in control group, $197.86 \pm 12.14$ minutes in fentanyl group and the dexamethasone group reported $311.43 \pm 13.59$ minutes of sensory blockade which was statistically significant $(p<0.0001)$. Our cohort comprised of 105 patients divided in three groups, whereas Fayyaz and colleagues had 60 patients divided into two groups.

In another randomized, prospective, double-blinded clinical trial, Movafegh and coworkers evaluated the prolongation of lidocaine spinal anesthesia by intrathecal administration of dexamethasone in 90 patients scheduled for orthopedic surgery [14]. They reported that the duration of sensory block was significantly longer in the lidocaine-epinephrine and lidocaine-dexamethasone groups than the lidocaine alone group. These results were similar to our study with respect to motor and sensory blockade; control group: 83.0 \pm 14.46 minutes vs $115.29 \pm 14.60$ minutes; fentanyl group: $163.86 \pm 12.49$ minutes vs $197.86 \pm 12.14$ minutes and the dexamethasone group: $223.43 \pm 16.96$ vs $311.43 \pm 13.59$ minutes. Thus, contributed to our hypothesis that the addition of dexamethasone intrathecally as an adjuvant to bupivacaine in spinal anesthesia prolongs the duration of sensory and motor blockade. The only difference in above studies was, we used hyperbaric bupivacaine whereas Movafegh and colleagues used lidocaine for spinal anesthesia.

Kikuchi A et al. studied 25 patients with post-herpetic neuralgia (PHN) of more than 1 year who were randomly allocated to one of two groups: an intrathecal group $(n=13)$ and an epidural group $(n=12)$. The improvements were much greater in the intrathecal group than in the epidural group at all-time points after the end of treatment $(p<0.005)[15]$. Moreover, IL-8 in the CSF decreased significantly in the intrathecal group as compared to the epidural group at the l-week time point $(p<0.01)$, whereas the other cytokines were undetectable suggesting that intrathecal MPA improves analgesia by decreasing an ongoing inflammatory reaction in the CSF [15]. This indirectly supported our study as the time to rescue analgesia was much higher in dexamethasone group as compared to fentanyl and control groups. Also, intrathecal dexamethasone may influence intraspinal prostaglandin production. Corticosteroids are capable of reducing prostaglandin synthesis by inhibition of phospholipase A2 through the production of calcium-dependent phospholipid-binding proteins called annexins and by the inhibition of cyclooxygenases during inflammation [16].

Numerous other studies in literature can be found supporting that steroids have powerful anti-inflammatory as well as analgesic property [17,18]. Mirzaie et al. reported that corticosteroids and bupivacaine can diminish the incidence of back pain after laminectomy in the immediate postoperative period [19]. Kotani et al. administered methylprednisolone with bupivacaine intrathecally in patients with PHN. They concluded that this combination induced excellent and long-lasting analgesia [20].

In a randomized study by Thomas and Beevi, 94 patients undergoing laparoscopic cholecystectomy were divided into three groups and post-operative morphine requirements, VAS pain scores at rest and with effort, and time to first analgesic administration were recorded [21]. They reported total morphine consumption for the first 24 hours following surgery was lower in both epidural dexamethasone groups (D1, D2) compared to the control group $(\mathrm{p}<0.05)$. The percentage reduction in morphine consumption in Group D1 was $53.9 \%$ and in Group D2 was $52.9 \%$ in the first 24 hours. These values were in accordance to our observations. About 30 (28.57\%) patients in our study required rescue analgesia within four hours after the surgery. Rescue analgesia was given within two hours in 10 patients, eight patients had pain within three hours after surgery and only one patient did not have pain until four hours after surgery in control group. Eleven patients in fentanyl group required rescue analgesia within four hours; however, in dexamethasone group, none required rescue analgesia in the first four hours. Prolonged duration of analgesia with significantly delayed time of administration of rescue analgesia was observed in dexamethasone group compared to fentanyl and normal saline groups.

Similarly, Bani-Hashem et al. conducted a randomized prospective clinical trial on 50 patients scheduled for orthopedic surgery under spinal anesthesia [9]. Sensory block duration in the case group was $119 \pm 10.69$ minutes and in the control group was $89.44 \pm 8.37$ minutes which was significantly higher in the case group (p $<0.001$ ). Although our results were equivocal on sensory block duration of $115.29 \pm 14.60$ minutes in control group, 197.86 \pm 12.14 minutes in fentanyl group and $311.43 \pm 13.59$ minutes in dexamethasone group, they 
reported the frequency of complications was not different between two groups but our cohort showed statistically significant observations with respect to complications like nausea/vomiting, bradycardia, shivering, etc. In our study, two patients in control group, four patients in fentanyl group complained of nausea/ vomiting; pruritus was reported in seven patients in fentanyl group; shivering was observed in three patients in fentanyl group and one patient in control group; one patient in control group had bradycardia which was managed with injection atropine $0.6 \mathrm{mg}$; two patients in dexamethasone group had hypotension whereas one patient each in fentanyl and control group had hypotension which was managed with injection mephentermine $6 \mathrm{mg}$. None of the patients in the dexamethasone group had nausea or vomiting. This result may be due to the antiemetic effect of dexamethasone, which has been demonstrated in other studies using perioperative corticosteroids [22,23].

In a double-blind, placebo-controlled study by Bisgaard and colleagues, 88 patients were randomized to intravenous dexamethasone $(8 \mathrm{mg}$ ) or placebo 90 minutes before lap cholecystectomy and the duration of stay at the PACU in dexamethasone group was 75 minutes (range 25-169) and in placebo group was 70 minutes (range 15-240 minutes) which was not significantly different between the two groups [24]. On contrary, in our study dexamethasone group stayed on an average for $233.14 \pm 17.28$ minutes, fentanyl group for $173.86 \pm 12.49$ minutes and $93.00 \pm 14.46$ minutes in control group in PACU and this difference was significant statistically. This difference was mainly due to our strict discharge criteria i.e stable vital signs, signs of regression of the motor block (Bromage 0 to 2), no analgesia needed within the previous $20 \mathrm{~min}$, and once patients attained all of the following criteria then only, they were shifted. Also, all patients voided normally without any need for catheterization. The control group took $203.00 \pm 19.71$ minutes, the fentanyl group took $315.29 \pm 21.18$ minutes at self-voiding of urine. However, patients in dexamethasone group, took $400.00 \pm 29.13$ minutes to self-void and the difference was statistically significant in our cohort $(\mathrm{p}<0.0001)$. The reason for a longer time to self-void may be due to prolonged time taken for regression of sensory and motor blocks in dexamethasone group.

Literature reported contrary studies regarding the safety profile of intrathecal steroids. In animal experiments, triamcinolone did not induce spinal neurotoxicity, whereas repeated high-dose intrathecal injections of betamethasone caused histopathological changes of the spinal cord $[25,26]$. However, intrathecal injection of steroids was frequently used for the treatment of mumps meningitis, chronic lymphocytic leukemia and central nervous involvement in lupus erythematosus [27]. We did not report any considerable complication for intrathecal dexamethasone. Similarly, Kotani et al. found no complication in patients who received intrathecal methyl prednisolone [20]. Also, Sugita and colleagues did not find any complication after intrathecal injections of dexamethasone in patients with posttraumatic visual disturbance [28]. However, further studies with longer follow-up are needed to verify the safety profile of intrathecal dexamethasone.

\section{Conclusions}

Although both fentanyl and dexamethasone prolong the duration of sensory and motor blockade in spinal anesthesia; however, dexamethasone could be a better alternative as it provides stable hemodynamic profile with minimal side effects. Longer motor blockade, time to self-void and longer PACU stay might limit its use unless a better dose can be found. So, further studies are needed to evaluate the optimal dose as well as longterm safety of intrathecal dexamethasone.

\section{Additional Information \\ Disclosures}

Human subjects: Consent was obtained or waived by all participants in this study. Artemis Health Sciences Institutional Ethics Committee issued approval ECR/53/Inst/HR/2013/RR-16. Due approval Taken from Institutional Review Board and Ethics Committee. Animal subjects: All authors have confirmed that this study did not involve animal subjects or tissue. Conflicts of interest: In compliance with the ICMJE uniform disclosure form, all authors declare the following: Payment/services info: All authors have declared that no financial support was received from any organization for the submitted work. Financial relationships: All authors have declared that they have no financial relationships at present or within the previous three years with any organizations that might have an interest in the submitted work. Other relationships: All authors have declared that there are no other relationships or activities that could appear to have influenced the submitted work.

\section{References}

1. Raeder JC: Regional anaesthesia in ambulatory surgery. Can J Anaesth. 2001, 48:R51-R54. 10.1007/BF03028178

2. Brown DL: Spinal, epidural and caudal anesthesia, 7th ed. Miller's Anesthesia. Miller RD (ed): Churchill Living Stone, Philadelphia; 2010. 1611-1638.

3. Murali KT, Panda NB, Batra YK, Rajeev S: Combination of low doses of intrathecal ketamine and midazolam with bupivacaine improves postoperative analgesia in orthopedic surgery. Eur J Anesthesiol. 2008, 25:299306. 10.1017/S0265021507002645

4. Brockway MS, Noble DW, Sharwood-Smith GH, McClure JH: Profound respiratory depression after 
extradural fentanyl. Br J Anaesth. 1990, 64:243-245. 10.1093/bja/64.2.243

5. Yu SC, NganKee WD, Kwan AS: Addition of meperidine to bupivacaine for spinal anesthesia for cesarean section. BrJ Anesth. 2002, 88:379-383. 10.1093/bja/88.3.379

6. Alhashemi JA, Kaki AM: Effect of intrathecal tramadol administration post-operative pain after transurethral resection of prostate. Br J Anesth. 2003, 91:536-540. 10.1093/bja/aeg213

7. Golwala MP, Swadia VN, Aditi A, Dhimar, Sridbar NV: Pain relief by dexamethasone as an adjuvant to local anesthetics in supraclavicular brachial plexus block. J Anesth Clin Pharmacol. 2009, 25:285-288.

8. Tkachenko R, Pyasetska $\mathrm{N}$ : The efficiency of intrathecal dexamethasone for spinal anaesthesia in elective caesarean section . Reg Anesth Pain Med . 2019, 44:A192-A193. 10.1136/rapm-2019-ESRAABS2019.324

9. Bani-Hashem N, Hassan-Nasab B, Pour EA, Maleh PA, Nabavi A, Jabbari A: Addition of intrathecal dexamethasone to bupivacaine for spinal anesthesia in orthopedic surgery. Saudi J Anaesth. 2011, 5:382386. 10.4103/1658-354X.87267

10. Axelsson K, Gupta A: Local anaesthetic adjuvants: neuraxial versus peripheral nerve block. Curr Opin Anaesthesiol. 2009, 22:649-654. 10.1097/ACO.0b013e32832ee847

11. Glasser RS, Knego RS, Delashaw JB and Fessler RG: The perioperative use of corticosteroids and bupivacaine in the management of lumbar disc disease. J Neurosurg. 1993, 78:383-387. 10.3171/jns.1993.78.3.0383.

12. Droger C, Benziger D, Gao F, Berde CB: Prolonged intercostals nerve blockade in sheep using controlledrelease of bupivacaine and dexamethasone from polymer microspheres. Anesthesiology. 1998, 89:969-979. 10.1097/00000542-199810000-00022

13. Fayyaz MA, Khan AA, AliRL: Comparison between effect of bupivacaine and bupivacaine with dexamethasone on duration of analgesia in spinal anaesthesia for elective caesarean section. P J M H S. 2015, 9:979-982.

14. Movafegh A, Ghafari MH: A comparison of the sensory and motor blockade duration of intrathecal lidocaine 5\% plus epinephrine and lidocaine 5\% plus dexamethasone. Int J Pharmacol. 2005 1:346-369. 10.3923/ijp.2005.346.349

15. Kikuchi A, Kotani N, Sato T, Takamura K, Sakai I, Matsuki A: Comparative therapeutic evaluation of intrathecal versus epidural methylprednisolone for long-term analgesia in patients with intractable postherpetic neuralgia. Reg Anesth Pain Med. 1999, 24:287-293. 10.1016/s1098-7339(99)90101-3

16. Yao XL, Cowan MJ, Glawin MT, Lawrence MM, Angus CW, Shelhamer JH: Dexamethasone alters arachidonate release from human epithelial cells by induction of P11 protein synthesis and inhibition of phospholipas A2 activity. J Biol Chem. 1999, 274:17202-17208. 10.1074/jbc.274.24.17202

17. McCormack K: The spinal actions of nonsteroidal antiinflammatory drugs and the dissociation between their antiinflammatory and analgesic effects. Drugs. 1994, 47:28-45. 10.2165/00003495-199400475-00006

18. Ahlgren SC, Wang JF, Levine JD: C-fiber mechanical stimulus response functions are different in inflammatory versus neuropathic hyperalgesia in the rat. Neuroscience. 1997, 76:285-290. 10.1016/s03064522(96)00290-4

19. Mirzai H, Tekin I, Alincak H: Perioperative use of corticosteroid and bupivacaine combination in lumbar disc surgery. Spine. 2002, 27:343-346. 10.1097/00007632-200202150-00003

20. Kotani N, Kushikata T, Hashimoto H, et al.: Intrathecal methylprednisolone for intractable postherpetic neuralgia. N Engl J Med. 2000, 343:1514-1519. 10.1056/NEJM200011233432102

21. Thomas S, Beevi S: Epidural dexamethasone reduces postoperative pain and analgesic requirements . Can J Anaesth. 2006, 53:899-905. 10.1007/BF03022833.

22. Axelsson K, Johanzon E, Essving P, Weckström J, Ekbäck G: Postoperative extradural analgesia with morphine and ropivacaine. A double-blind comparison between placebo and ropivacaine $10 \mathrm{mg} / \mathrm{h}$ or 16 mg/h. Acta Anaesthesiol Scand. 2005, 49:1191-1199. 10.1111/j.1399-6576.2005.00715.x

23. Pham Dang C, Delécrin J, Péréon Y, Falconi I, Passuti N, Malinge M, Pinaud M: Epidural analgesia after scoliosis surgery: electrophysiologic and clinical assessment of the effects of bupivacaine $0.125 \%$ plus morphine versus ropivacaine 0.2\% plus morphine. J Clin Anesth. 2008, 20:17-24. 10.1016/j.jclinane.2007.07.007

24. Bisgaard T, Klarskov B, Kehlet H, Rosenberg J: Preoperative dexamethasone improves surgical outcome. Ann Sur. 2003, 238:651-660. 10.1097/01.sla.0000094390.82352.cb

25. Abram SE, Marsala M, Yaksh TL: Analgesic and neurotoxic effects of intrathecal corticosteroids in rats . Anesthesiology. 1994, 81:1198-1205. 10.1097/00000542-199411000-00013

26. Latham JM, Fraser RD, Moore RJ, Blumbergs PC, Bogduk N: The pathologic effects of intrathecal betamethasone. Spine. 1997, 22:1558-1562. 10.1097/00007632-199707150-00004.

27. Hunt CO, Naulty JS, Bader AM, et al.: Perioperative analgesia with subarachnoid fentanyl-bupivacaine for cesarean delivery. Anesthesiology. 1989, 71:535-540. 10.1097/00000542-198910000-00009

28. Sugita K, Kobayashi S, Yokoko A, Inoue T: Intrathecal steroid therapy for posttraumatic visual disturbance. Neuronchirurgia. 1983, 26:112-117. 10.1055/s-2008-1053622 